THE INTERNATIONAL

REVIEW OF RESEARCH IN

OPEN AND DISTANCE LEARNING

\title{
Motivating Factors that Affect Enrolment and Student Performance in an ODL Engineering Program
}
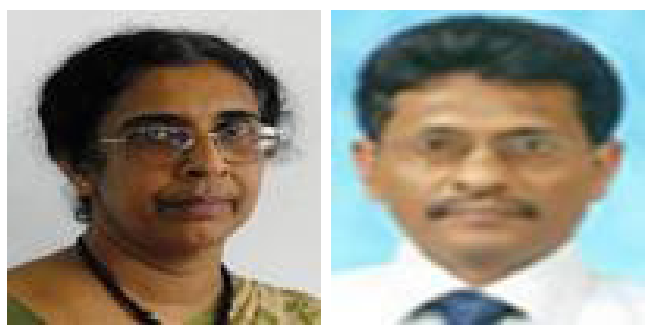

P.R. Dadigamuwa and SAMANS Senanayake The Open University of Sri Lanka

\section{Abstract}

The present study was carried out to determine the motivating factors for enrolling in an engineering study programme in open and distance learning (ODL) and the factors that affect the students' performance. The study was conducted with two convenient samples of students following distance learning courses in engineering technology, conducted by the Open University of Sri Lanka and leading to the award of diploma or degree in Engineering Technology. One sample consisted of students who failed to qualify for sitting the year-end examination and the other consisted of successful students.

The study showed that many students opt to follow the programme without knowing the relevance of the study programme for them. Most of the students (53\%) had taken the courses believing that they could obtain a recognized degree. The students with secondary education qualifications in the mathematics stream were found to be successful, provided that they had selected the ODL programmes with an understanding of the nature of the ODL system, the percentages being 61 with 4 passes, 75 with 3 passes, and 20 with 2 passes at the General Certificate in Education (Advanced Level) examination.

All successful students were of the opinion that the course delivery methods should be improved, especially face-to-face teaching, laboratory classes, and assignments.

Keywords: Distance learning; engineering; performance; motivating factors; Sri Lanka

\section{Introduction}

At present, higher education in Sri Lanka is faced with a problem of providing educational opportunities for those who do not gain admission to conventional national universities. The chance of securing a place in one of the study programmes offered by these universities 
is very low as more and more students compete to enter the universities through a tough competition at the G.C.E. (A/L) qualifying examination, whilst the available vacancies are not expanding in pace with the demand. In 2010 only $17.2 \%$ of the eligible students were admitted to national conventional universities. This is a common problem faced by many developing countries. As such, many educational institutions, including conventional universities, are taking initiatives to offer study programmes through open and distance learning (ODL) methods in parallel with on-campus programmes.

The Open University of Sri Lanka (OUSL) is the only recognized national institution in the country to offer ODL programmes. From its inception, the OUSL has offered study programmes for employed students. However, at present, ODL in Sri Lanka seems to be a viable and effective method of providing higher educational opportunities for everybody who desires to study while being employed, especially in a situation where the traditional universities are not in a position to cope with increasing demand. The high flexibility in course choice and the unrestricted completion time are making ODL more acceptable and popular among the students. However, as ODL programmes heavily rely on self-study, the students who choose ODL courses need to be well aware of the course delivery method and should be prepared to study with self-motivation.

Usually the number of students dropping out in a distance learning programme is significantly higher than that of a conventional study programme. As several factors affect the students' performance and subsequent dropout, continuous studies need to be carried out to find the root causes for poor performance in view of increasing the number of successful students. The main concern is for the causes for dropping out due to the nature of the present ODL practices, which the students find difficult to cope with and thus perform poorly.

Various researchers have carried out studies to develop models for predicting which students will likely drop out of ODL programmes. These models have limitations, especially when applied to different contexts and situations depending upon the political, economic, and social environment. Woodley suggested that rather than pursuing a general model, researchers need to conduct experiments to determine meaningful remedial actions for retention of students.

\section{Rationale for the Study}

The Faculty of Engineering Technology of the OUSL has been offering distance education courses in engineering for 20 years, being the pioneering institute in the world to offer engineering study programmes in distance mode. The student dropout rate has been high in the early years of the study programmes, which is more or less 50\% from year 1 to year 2 . Teachers, without proper study, attribute this high dropout rate to various factors such as nonpreparedness for self-study, lack of aptitude to the engineering discipline, lack of support on the part of faculty, and improper selection of courses at the beginning.

This study attempted to establish the exact reasons for the high dropout rate at early stages of the engineering technology programmes offered by the Faculty of Engineering Technology of the OUSL while determining the motivation factors for enrolment in the engineering 
study programme.

\section{Study Programme and Student Profile}

The study programme in Technology (Engineering) consists of courses from six academic levels and from different categories. Levels 1 and 2 are foundation levels. The course categories included in the present curriculum are Engineering, Mathematics, Engineering Projects, Management, General, Industrial Training, Computer Literacy, and English Language. The curriculum consists of core courses, which vary according to the field of specialisation, and other courses to be chosen from a list of courses to meet the credit requirements for an award as determined by the faculty.

The students who have passed G. C. E. (A/L) in the mathematics stream can omit courses at levels 1 and 2, and those who have higher qualifications may receive further exemptions from relevant courses. In an academic year, a student can register for up to 45 credits of courses (equivalent to 1,125 notional hours of study). Students need to collect 115 credits to receive the Diploma in Technology; whereas, 205 credits are necessary for the Degree. The total number of credits obtained is subjected to certain conditions so that a given minimum should be obtained from different categories of courses and levels.

The printed course materials prepared by the staff are the main and sometimes only instructional material for the courses. At registration the students are given the first set of course materials with relevant take-home assignments. The remaining course materials with assignments are issued to the students after three months, on the payment of the second instalment of course fees. There are a minimum of nine hours and maximum of 18 hours of scheduled face-to-face teaching sessions each of three-hour duration per course.

The students are assessed on a continuous basis by various assessment tools that differ according to the nature of the course. The most dominant assessment methods used at present are assignments (mostly in the form of tutorials), continuous assessment tests (CATs), laboratory work, student presentations and mini-projects. The eligibility to sit the final examination in respect of each course is based on the performance in continuous assessments. These assessments also provide an opportunity for the students to keep motivated and guide themselves towards achieving acceptable faculty standards. An overall continuous assessment mark (OCAM) is computed in respect of each course by combining the marks obtained by the students for various continuous assessment components administered throughout the academic year.

\section{Methodology}

The students who registered for the Technology (Engineering) programme of study at the OUSL that leads to the award of a Diploma in Technology and a Bachelor of Technology (Engineering) were the experimental group selected for the study.

Two convenient samples of students aged below 30 years were selected for the study. The number of students in each sample was 40. One sample consisted of those who did not ob- 
tain eligibility to sit the year-end examinations in any one of the courses offered. The other group consisted of successful students in obtaining eligibility to sit the year-end examination in all the courses. A well-structured questionnaire together with discussions was used to collect information. The areas covered were student profile, reflecting such factors as age, prequalifications, gender and employment, feedback on course delivery, factors that motivated the students to enrol in the programme, and awareness of the ODL programmes at the time of enrolment.

\section{Results}

\section{Motivating Factors for the Selection of ODL Programmes}

\section{Programme recognition.}

Most of the students indicated that recognition and flexibility were the reasons for selecting the programme: $42 \%$ from among the successful students indicated recognition as the main reason for selection of the programme, of which $34 \%$ had four passes in the G.C.E. (A/L) examination. For unsuccessful students, this was $53 \%$, of which $31 \%$ had 4 passes in the G. C. E. (A/L) examination. This indicates that even a fair number of "good" students who selected the engineering study programmes because of mere recognition have failed in ODL. So the general understanding that the students with passes in the G.C.E. (A/L) can cope better in ODL than others is questionable. More importantly, students should have good reasons as well as knowledge of ODL together with the necessary background subject knowledge to succeed in the ODL programme in engineering.

The acceptance of the OUSL-ODL engineering programme in terms of recognition and flexibility is a positive and encouraging factor to the faculty. However, enrolment of students in the programme after considering recognition only is problematic. 


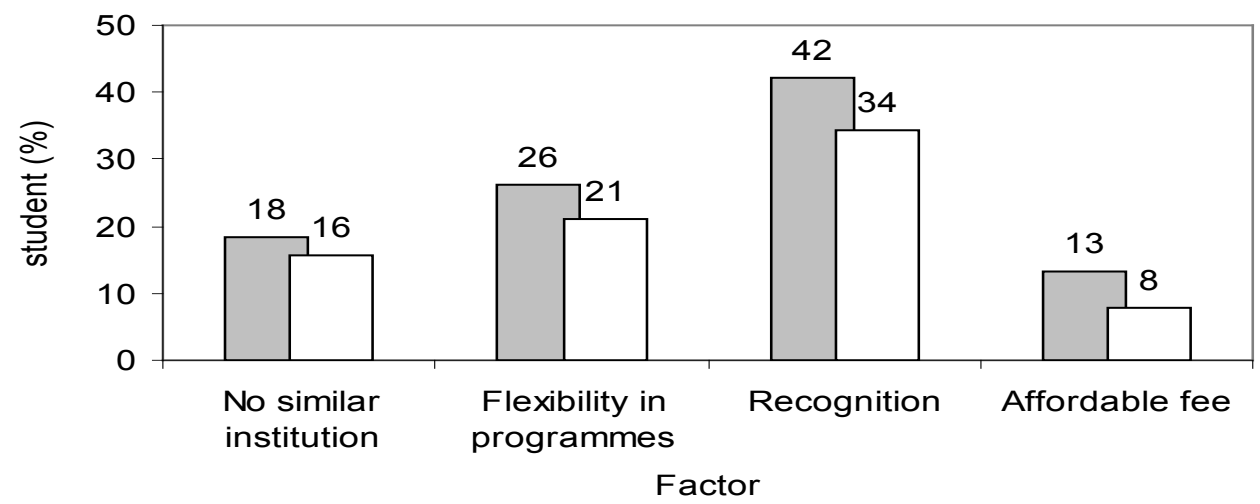

\% student $\square$ Students with 4 passes at GCE (A/L) examination

Figure 1. Factors affecting the enrolment (successful students).

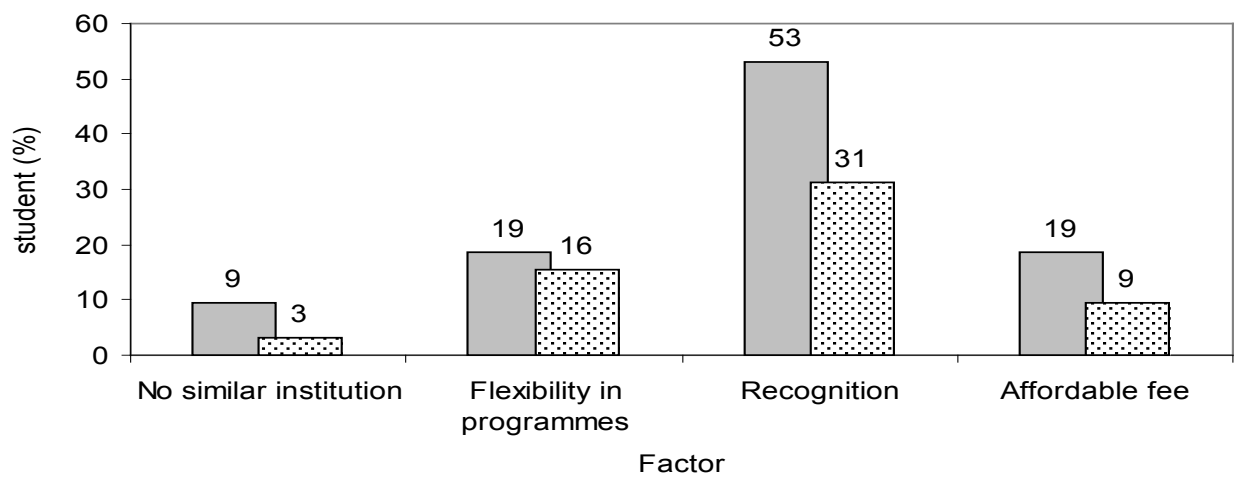

$\square \%$ student $\quad$ S Students with 4 passes at GCE (A/L) examination

Figure 2. Factors affecting enrolment (unsuccessful students).

The students normally consider recognition of a qualification as a key factor in order to secure high-demand employment. In the case of employed students who pursue higher studies for career prospects, the relevance of such programmes plays a major role rather than mere recognition. Enrolling in the ODL programmes because of recognition only, without having proper knowledge of the nature of the study methods, causes difficulties for the teachers and the students themselves. Accompanying high rates of failure, as a consequence, will unfavourably impact on the institution as well as on ODL in general. The faculty in this environment is clever enough to look to students' competence and implement alternative methods of course delivery without deviating much from the distance-learning concept. As many school leavers are joining ODL programmes and they are not familiar with self-learning, in many instances they demand more face-to-face teaching as practised in conventional degree programmes, which can never be met with the limited space and teachers available. But faculty should consider providing them with enhanced student sup- 
port possibly as discussion sessions and web-based interactive learning.

\section{Flexibility in study programmes.}

Flexibility was indicated as the second motivating factor to enrol in the OUSL-ODL engineering programme: $26 \%$ for successful students and $19 \%$ for unsuccessful students. The flexibility in course selection and the time duration for completion are usually welcomed by students as this provides them with room to follow other courses and to be employed.

Flexibility is an essential feature in any ODL programme, especially for the benefit of employed students. The flexibility in time period for completion is needed as these programmes are open for all types of students with different ages, incomes, family engagements, and previous knowledge. Diverse requirements by industry demand a wide range of courses and flexibility in the selection.

\section{Affordable fee structure.}

Affordable course fee was the third most influential factor for enrolment (13\%) for successful students; whereas, for unsuccessful students this was rated the same as flexibility in course selection (19\%). The study proved that students are prepared to pay for courses that are recognized and could be followed without interrupting their other commitments. Another reason for placing course fee in third place could be that flexibility allows students to earn money while studying.

Course fee depends on the total cost incurred in the development and delivery of courses and the government subsidy. Developing open and distance learning programmes involves high expenditures as it is a long process of designing, developing, testing, and implementing. In spite of its initial cost, ODL is considered to be cost effective because a large number of students can benefit, making the cost per student low. The cost incurred in the development process and the recurrent cost, which includes direct costs of print, audio, video etc, is recovered from the course fees. Though the course fees in ODL courses are less than that of a conventional programme, this amount too is sometimes not affordable to the students in developing countries like Sri Lanka. Therefore, a part of the ODL expenditure has to be borne by the government as distance education immensely contributes to the national educational needs of the nation, which in turn contribute in a productive manner to the national, economic, and social development of the country. In recognition of this fact fees charged for ODL programmes in Sri Lanka have been kept to a minimum. Usually the students pay only one third of the actual cost. This is much less than the private sector conventional-type study programmes. This is one reason that a large section of the population chooses distance learning programmes, giving less attention to the real nature of the system in which students' commitment, self-motivation, and relevance are very important but are ignored.

\section{Nonexistence of similar institutions.}

Eighteen percent and 9\% from successful and unsuccessful students respectively indicated 
that the deciding factor was the nonavailability of similar institutions offering study programmes in engineering.

The OUSL, being the only recognized institution in Sri Lanka to offer ODL programmes, at present, has the great advantage of attracting good students because of its recognition by the students as a government institution. However, it is also clear that if there were other avenues for students to turn for their higher studies, the OUSL would lose many students. Under these circumstances the University will have to critically consider the factors influencing students' failure, without blaming the unqualified students who are being enrolled, which is a perception of a significant number of staff members.

\section{Performance Based on Level of Secondary Education}

The students' performance at the G. C. E. (A/L) examination in the mathematics stream was examined with the successful studying in the ODL programme. In this study the number of students gaining eligibility (EL) or noneligibility (NE) is related to the number of passes the students obtained at their G.C.E. (A/L) examination.

In the sample selected, $77 \%$ of students had 4 passes in the G.C.E. (A/L) examination, of which $61 \%$ were successful. Eighty percent of the students were unsuccessful from among those who had only 2 passes. This is a clear indication that the students with good performance in secondary education can cope better in ODL than poorer performing students. It is unsurprising that those who have made a commitment and are prepared to face challenges in the highly competitive G.C.E. (A/L) examination can proceed without any difficulty in ODL programmes as well.

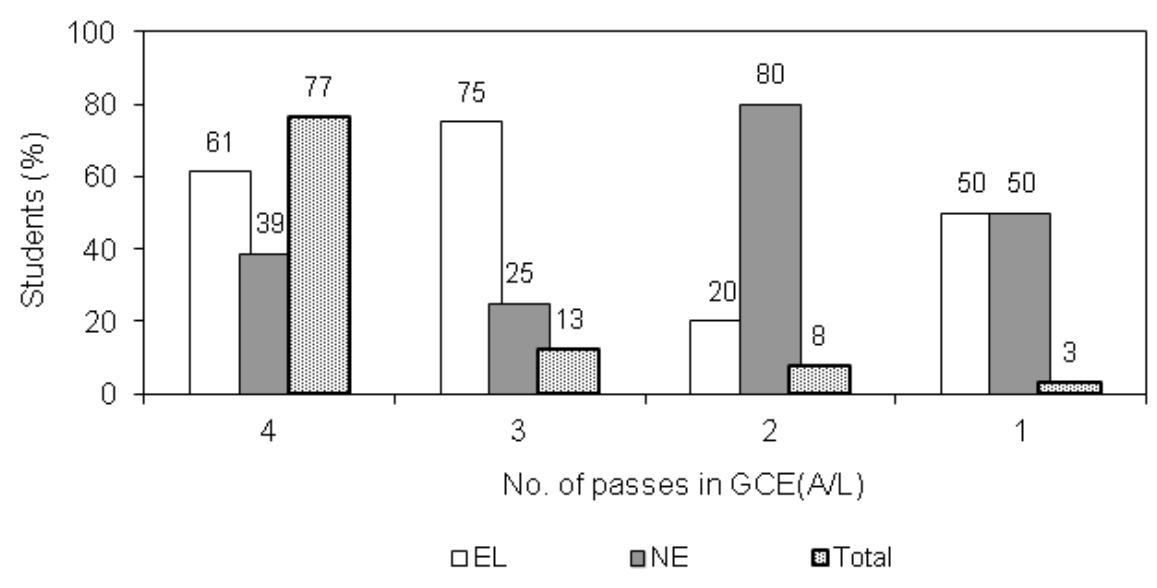

Figure 3. Performance of students according to passes in G.C.E. (A/L) examination.

Young students with successful secondary education do better in distance education programmes and therefore it is the responsibility of the faculty to recognize their commitment and capabilities and remove unnecessary constraints imposed on credits per year and inappropriate course prerequisites. This type of restructuring in ODL programmes is needed for the benefit of the students who are not employed and have performed well in secondary 
education and are joining the ODL programmes not as a second choice but as their first choice because of specific advantages of the ODL programmes. At the same time, the opportunity opened for employed students should remain as a second chance for them to study towards recognized degrees and secure employment prospects.

\section{Awareness of Students of ODL Programmes at OUSL}

Most students were aware of the main features of the study method adopted in ODL. Only $41 \%$ of students knew about the continuous assessment methods and the programme duration at the time of enrolment.

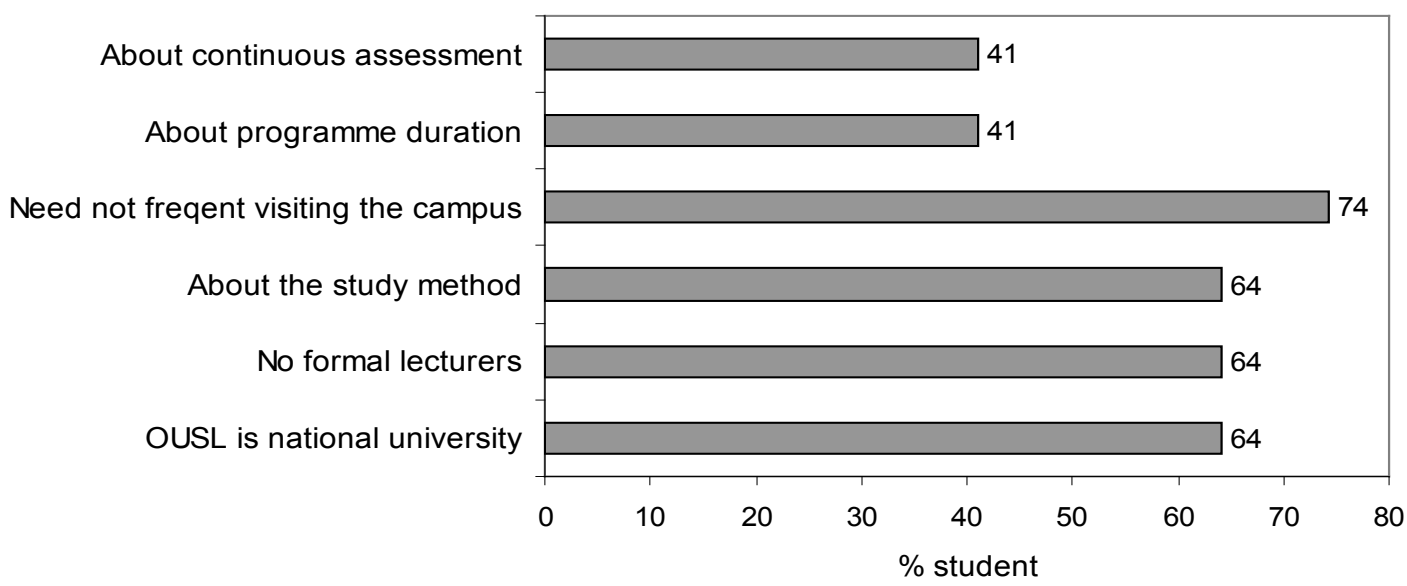

Figure 4. Awareness of the students about the ODL programmes.

\section{Students' Feedback on Course Delivery}

The students questioned on different aspects of course delivery responded quite consistently, giving their overall attitude towards the ODL as well as shortcomings of the delivery system. Course delivery in ODL includes providing instructional materials as well as guiding students by various means such as assignments, classroom tests, group projects, personal tutoring, and feedback. The main medium for bridging the gap between the teacher and the student in this programme of study is printed materials. The students were critical of the language, subject content, depth of subject matter, and readability of the print. 


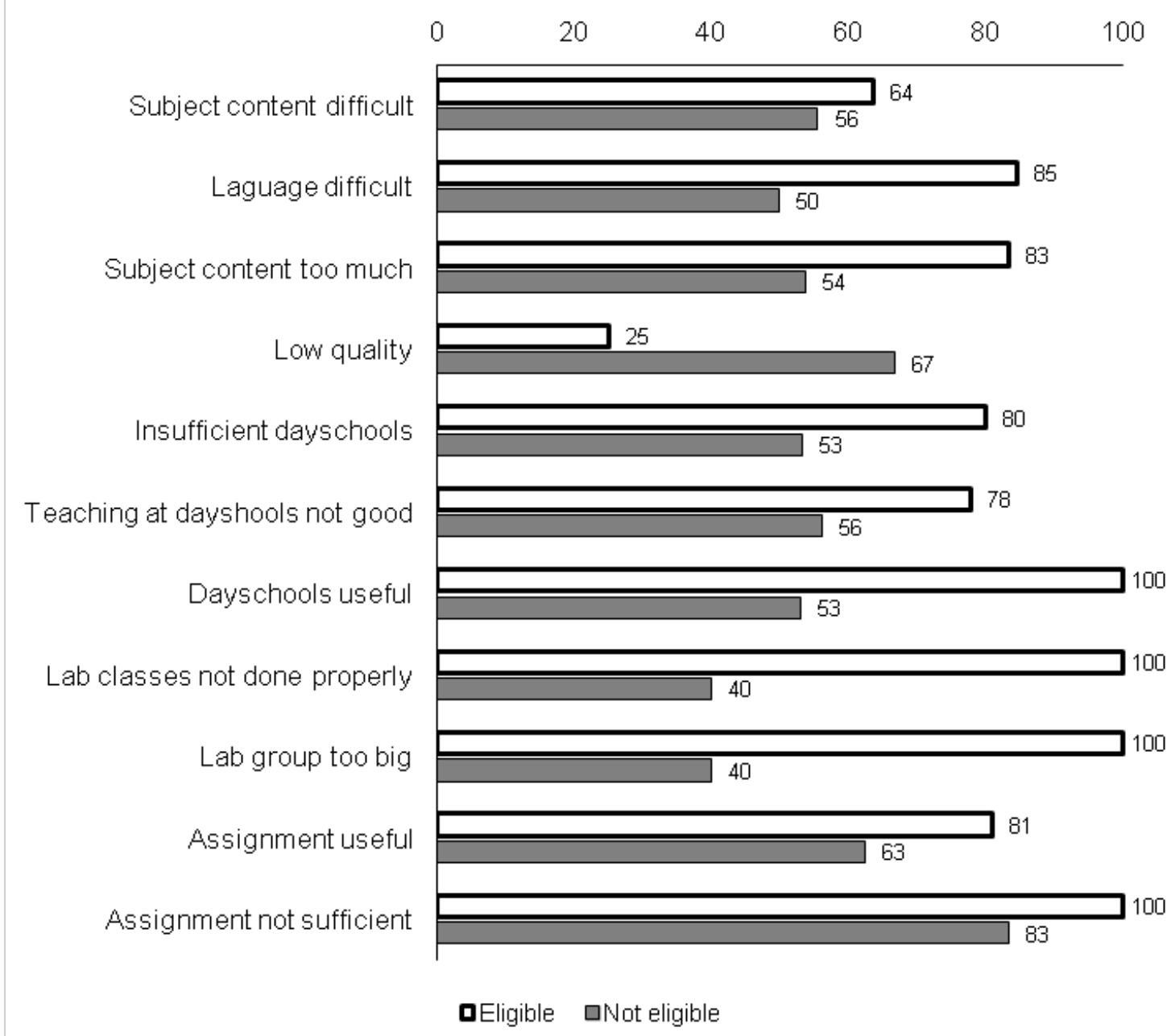

Figure 5. Students' response to different aspects in distance teaching.

Most successful students were not satisfied with many aspects of the course delivery and associated activities. They were particularly concerned about difficult subject content, too much subject content, language difficulty, insufficient day classes, and large lab groups. More importantly, all successful students indicated that the day schools were useful, but $78 \%$ said teaching at the day schools was not good. A serious concern was that all the successful students responded negatively to lab classes, indicating that lab classes were not properly done and class sizes were too large. With regard to assignments, all successful students were of the view that the number of assignments was not sufficient; $81 \%$ said assignments were useful. Generally, the students responded negatively to course delivery aspects, indicating difficult subject content (64\%), language difficulty (85\%), and too much subject content (83\%).

\section{Discussion and Conclusions}

The study revealed that many students had chosen the ODL programme in engineering because of the recognition of the OUSL awards (53\%). This is not surprising given the present situation in the country. When choosing a study programme, everyone's deciding factor 
is directed towards finding a job which requires a recognized qualification. Many students who have no mathematical background at the secondary education level opt to enroll for technology programmes especially computer technology with the opinion that Engineering or Technology qualifications are in high demand in the job market.

A majority of students with good G. C. E. (A/L) examinations was successful in obtaining eligibility to sit the year-end examinations. The students having good G. C. E. (A/L) but who failed in ODL courses had selected the programme possibly based on incorrect reasons. While accepting that the G.C.E (A/L) qualified students can do better in the ODL engineering programme, they should be made aware of the ODL system before enrolling. At the same time, other students should be taught engineering foundation courses with more face-to-face teaching and gradually shifted to the complete ODL methods.

The least influential factors in selecting the ODL engineering programme were the nonexistence of similar institutions offering programmes suited to their needs and the course fees. This is a positive aspect of OUSL study programmes.

With regard to key features of course delivery, the faculty should rectify the shortcomings of face-to-face teaching sessions, lab classes, continuous assessment tests, and course materials. The faculty is responsible for providing necessary course materials and course guidance according to a well-defined timetable to make sure that the students follow the courses in a fruitful manner. It is also the duty of the staff to support the students to solve problems related to programme administration. In this sense distance teaching needs more responsibility on the part of academics than conventional teaching.

Therefore in an ODL system everything needs to be planned beforehand, and anticipated difficulties should be identified in advance. Although the successfulness of an ODL programme is heavily dependent on the student approach and commitment, the responsibility of the academic staff cannot be diluted.

The students need to have a number of characteristics, such as tolerance for ambiguity, a need for autonomy, and an ability to be flexible, in order to be successful in ODL. Further, they need to be focussed, strong time managers, and capable of working independently with group members. Many distance learners are different from traditional undergraduates because they are already in professions. They have well-defined goals and are more motivated. However, many students undertaking ODL programmes are not meeting these requirements, and naturally the programmes designed for mature experienced students do not suit them.

Students' erroneous perception of ODL was one of the reasons for unsuccessfulness in distance learning. Some less important factors lead students to select study programmes in distance learning without careful thought given to their readiness to adjust to the system. This will result in failure in courses. The fact that the study programmes in distance learning need more student commitment, self-motivation, good time management, and group learning skills are usually undermined, and factors like recognition of the awards, flex- 
ibility, and comparatively low fees play a great role in attracting more students, especially when there are very few avenues for higher studies. 


\section{References}

Ashby, A. (2004). Monitoring student retention in the Open University: Detritions, measurement, interpretation and action. Open Learning, 19(1), 65-78.

Barat, I.F., Lalita, S. Kumar, \& Kannan, S. (2006). A survey of a study on the reasons responsible for student dropout from the Bachelor of Science Programme at Indira Gandhi National Open University. International Review of Research in Open and Distance Learning, 3(1).Retrieved from http://www.irrodl.org/index.php/irrodl/ article/view/291/755

Barefoot, B. O. (2004). Higher education revolving door: Confronting the problem of student dropout in US colleges and university, Open Learning, 19(1), 9-18.

Brown, K.M. (1996). The role of internal and external factors in the discontinuation of off campus students. Distance education, 17(1), 44-71.

Dibiase, D. (2000). Is distance education a Faustian bargain? Journal of Geography in Higher Education, 24(1), 130-136.

Powel, R. (1991). Success and persistence at two open universities. Center for Distance Education: Athabasca University.

Threlkeld, R. \& Brezoska, K (1994). Research in distance education. In Willis, B., Distance education strategies and tools. Englewood Cliffs: Educational Technology Publications.

Woodley, A. (2004). Conceptualizing student dropout in part-time distance education: Anthologizing the normal? Open Learning, 19(1), 47-64.

\section{Athabasca University $\mathbf{a}$}

